\title{
Augmentation of managed populations of Osmia cornuta and O. rufa (Hymenoptera: Megachilidae) in Southeastern Europe
}

\author{
MiLOJE KRUNIĆ and LJUBIŠA STANISAVLJEVIĆ* \\ Institute of Zoology, Faculty of Biology, University of Belgrade, Studentski trg 16, 11000 Belgrade, Serbia and Montenegro; \\ e-mail: Ljstanis@bf.bio.bg.ac.yu
}

Key words. Hymenoptera, Megachilidae, orchard bees, pollination, Osmia cornuta, Osmia rufa, augmentation, soil watering, Serbia

\begin{abstract}
We describe augmentation of managed populations of Osmia cornuta and O. rufa in the vicinity of Belgrade (Serbia). Annual augmentation of $O$. cornuta populations was more than five-fold during the six years of our study. This was achieved by watering the soil near the Osmia augmentation shelters used for nest building. However, populations of $O$. rufa under the same treatment only doubled annually. Data are also presented on sex ratios in these managed populations, the sex ratio being an important factor in increasing population numbers and raising pollination efficacy. Sex ratio values ( $\delta: q)$ varied from $1.46: 1$ to $3.22: 1$ in the populations of O. cornuta and from $1.35: 1$ to $2.68: 1$ in those of $O$. rufa.
\end{abstract}

\section{INTRODUCTION}

A number of species of orchard bees are used commercially as pollinators in many countries. However, in view of its effectiveness, the practice can still be considered inadequately employed, especially in the Southeastern Europe, where - in contrast to the United States (Torchio, 1976; Batra, 1998; Bosch \& Kemp, 2002) and Japan (Maeta \& Kitamura, 1974; Sekita, $2001)$ - the tradition of commercial use of bees as pollinators is weakly developed at this time.

Previous to the current study, we attempted to augment Osmia cornuta and $O$. rufa populations in orchards. After efforts lasting several years, our population oscillated within the limits of 20,000 to 30,000 cocoons (Krunić et al., 1987). Reproduction of $O$. cornuta and $O$. rufa requires the presence of suitable nesting material [bundles of the common reed Phragmites australis (Cav.) ex Steud. and lamellar boxes (Krunić et al., 1995)] and abundant pasture (mainly fruit trees with extended flowering periods) in places less exposed to winds. However, even though we carefully selected such places over a long period of time (several years), we did not succeed in increasing the population to a level higher than about 50,000. It seemed at the time that dispersion of females was a significant constraint on population during this period (Bosch, 1994; Krunić et al., 2001). We chose to test this assumption by studying augmentation of $O$. cornuta and $O$. rufa in the vicinity of Belgrade (Serbia) by examining whether, alternatively, the sex ratio of both species in the managed populations is a factor important for augmentation.

\section{MATERIAL AND METHODS}

Cocoons were collected from naturally occurring populations of $O$. cornuta (Latr.) and $O$. rufa (L.) in places where they are usually found in abundance. This was most often around houses and other buildings roofed with the reed P. australis. Empty nesting material was placed as trap nests under the eaves of such buildings. The trap nests most often consisted of wooden blocks with inserted paper tubes $(8 \mathrm{~mm}$ in diameter and $15 \mathrm{~cm}$ in length) and bundles of common marsh reeds.

We found it easiest to achieve augmentation of our populations of $O$. cornuta by forming shelters out of numerous bundles of the marsh reed P. australis and lamellar boxes. The shelters were put in places protected from strong winds among an abundance of fruit trees blooming at different times, including almond, apricot, cherry, plum, pear, apple, medlar, and quince. We called such a shelter an "Osmia augmentation shelter" (OAS). At the Grocka locality, an OAS with total height of $3 \mathrm{~m}$ was composed of four wooden stakes driven into the ground. Stakes were placed in each corner of each rectangular shelter ( $0.6 \mathrm{~m}$ in width and $3 \mathrm{~m}$ in length). Within the corners formed by these stakes were two planks, the first of which was positioned $1 \mathrm{~m}$ above the ground and supported by one central stake, while the second one was $1 \mathrm{~m}$ above the first. The entire structure was covered with a roof which protected nesting material from direct sunlight, rain, and wind (Fig. 1). During each season, 200 bundles of reeds were put on the first plank of the shelter; each consisted of 100 tubes with nodes in the middle and openings on both ends. The reed tubes differed in diameter and in depth, which ranged from 5 to $9 \mathrm{~mm}$ and from 15 to 25 $\mathrm{cm}$, respectively. Twenty lamellar boxes each measuring $15 \mathrm{~cm}$ in width, $20 \mathrm{~cm}$ in height, and $12 \mathrm{~cm}$ in depth were put on the second plank and contained 120 tubes which were $8 \mathrm{~mm}$ in diameter and $12 \mathrm{~cm}$ in length (Krunić et al., 1995).

The area of ground close to the shelter was heavily watered every morning and evening during periods of bee nesting activity. When the fruit trees started to bloom, cocoons were transferred from a cold room to OASs at intervals of 7-15 days (on March 24 and April 2 in 1994; on March 10 and 25 as well as April 4 and 18 in 1995; on April 10 and 17 in 1996; on March 3, 16, and 25 in 1997; on April 5 and 20 in 1998; and on April 2 and 10 in 1999). The total number of cocoons per monitored shelter was about 10,000 to 15,000 (Table 1). Storing of cocoons at appropriate temperatures during the period of hibernation is of great importance not only for emergence dynamics, but also for individual viability, on which both successful pollination and augmentation depend (Bosch \& Blas, 1994; Bosch \& Kemp, 2000; Kemp \& Bosch, 2000; Krunić et al., 2001). Temperatures in the cold room where cocoons were stored ranged from $2-6^{\circ} \mathrm{C}$, and $\mathrm{RH}$ was about $50-60 \%$. When cocoons were transferred to OASs at the end of February or in the first half of March, at which time almond and apricot trees often started blooming, they were stored at $4-6^{\circ} \mathrm{C}$. The cocoons used at the

\footnotetext{
* Corresponding author.
} 


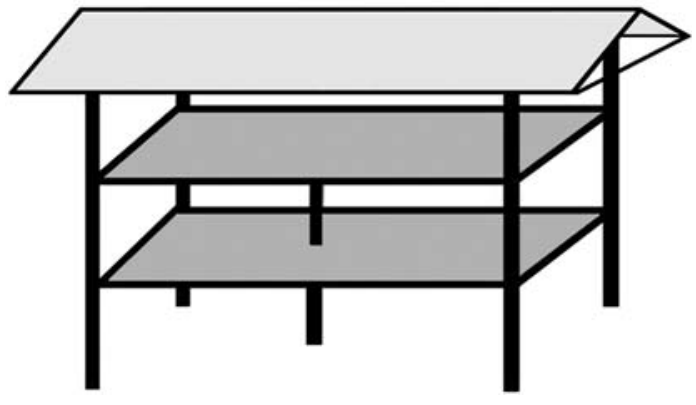

Fig. 1. Drawing of Osmia augmentation shelter (OAS).

end of March or in April, when apple trees most often bloom, were stored at $2-3^{\circ} \mathrm{C}$. A week before transferring cocoons to OASs, the temperature in the cold room with cocoons was raised to about $10^{\circ} \mathrm{C}$.

Cocoons were transferred to shelters in cardboard boxes with slits through which the bees could fly out. The boxes with cocoons in the shelter were protected from direct sunlight, rain, insectivorous birds, and mice. Smaller numbers of cocoons were transported in cardboard boxes because bees defecate immediately at emergence, which could foul unemerged and newly emerged bees. The cocoons were carried in layers of 3 to $4 \mathrm{~cm}$. After sampling emergence rates, boxes with empty cocoons were burnt because their odour attracted many predators. By successively transferring cocoons several times within a short period ( 7 days), we were able to avoid the adverse effects of unfavourable weather conditions, which could sometimes decimate emerging females. This approach to augmentation was applied to manage populations from 1994 to 1999 for $O$. cornuta and from 1996 to 1999 for O. rufa in the vicinity of Grocka.

The total number of stripped $O$. cornuta cocoons from each OAS was estimated by randomly selecting 10 samples $(100 \mathrm{ml})$ and extrapolating for the entire volume of cocoons in the OAS. Results are presented as values of the sample mean and the standard error.

The sex ratio in $O$. cornuta was followed at Grocka during the period of 1994-1999, while in O. rufa it was monitored at the same locality from 1996 to 1999 . Sex ratios were determined on samples of cocoons randomly taken from the same OAS; each unemerged cocoon was placed in a small chamber $(1 \times 1 \times 1 \mathrm{~cm})$, and incubated. The sex ratio was calculated after this method was repeated several times.

\section{RESULTS}

After accidental bursting of a water main and subsequent moistening of the soil surrounding a building with managed populations of $O$. cornuta and $O$. rufa in the vicinity of Belgrade, a large number of females were observed taking mud and carrying it off to their nests. Reeds left under eaves of that building in only a week's time after the previous checking had tunnels that were almost $90 \%$ completed. Just a week before, the same reeds were only about $10 \%$ filled. That same day, around buildings several hundreds of meters away from the indicated place (where pasture conditions were similar, but the soil was not moistened), the filling of nesting material was found to range from 10 to $30 \%$. All this happened during a period of warm and sunny weather without precipitation, when the soil in blooming orchards was fairly dry. In subsequent years, the method of soil watering was used to produce O. cornuta in the hundreds of thousands from relatively small initial populations. Evidently, abundant pasture and fair, warm weather ordinarily are not enough to produce optimal circumstances for augmentation of $O$. cornuta under our climatic conditions.

Augmentation of managed populations of Osmia cornuta and $O$. rufa was very different during the period of investigation (Table 1). That of $O$. cornuta increased more than five-fold (5.36- to 7.79-fold). On the other hand, O. rufa numbers only doubled at the same locality. The augmentation of $O$. cornuta in OASs during the study was never less than fivefold in relation to the number of cocoons taken outdoors (Table 1). In some years, the majority of bundles and lamellar boxes set out in OASs exhibited almost $100 \%$ nest fill. Under conditions of constant watering of the soil (several times a day when warm dry winds were blowing), the population of $O$. cornuta in our OASs multiplied as much or more than sevenfold in some years (Table 1).

After several years of practice in propagating these bees with supplementary watering of the soil, only $O$. cornuta reproduction can be elevated through augmentation, which can be seen from Table 1. Of all cocoons stripped in the fall from OASs, only up to $4 \%$ were cocoons of $O$. rufa.

The sex ratio $(\hat{\delta}: \stackrel{q}{)})$ in our managed populations of $O$. cornuta and $O$. rufa at the monitored locality (Table 1) varied from $1.46: 1$ to $3.22: 1$ and $1.35: 1$ to $2.68: 1$, respectively. It can

TABLE 1. Multiplication and sex ratios in managed populations of Osmia cornuta and O. rufa in Grocka (20 km southeast of Belgrade); ( $\mathrm{Ni}$ - number of introduced cocoons, RE - rate of emergence, Ns - number of stripped cocoons, RM - rate of multiplication, $\bar{x}$ - mean, s.e. - standard error of the mean, $(\mathrm{N})$ - number of samples, $(\mathrm{n})$ - size of samples.

\begin{tabular}{lcccccc}
\hline \multicolumn{1}{c}{ Year } & $\mathrm{Ni}$ & $\mathrm{RE}(\mathrm{n})$ & $\mathrm{Ns}$ & $\mathrm{RM}$ & $\bar{x} \pm$ s.e. $(\mathrm{N})$ & \multirow{0}{*}{ ᄋ $(\mathrm{n})$} \\
\hline Osmia cornuta & & & & & & \\
\hline 1994 & $\sim 10000$ & $71.35(1522)$ & 77910 & $\sim 7.79$ & $245.00 \pm 5.81(30)$ & $1.58: 1(400)$ \\
1995 & $\sim 10000$ & $82.51(1738)$ & 61997 & $\sim 6.19$ & $251.00 \pm 4.50(30)$ & $1.97: 1(400)$ \\
1996 & $\sim 14000$ & $93.99(1381)$ & 75081 & $\sim 5.36$ & $258.90 \pm 4.68(30)$ & $3.22: 1(400)$ \\
1997 & $\sim 14000$ & $78.42(2534)$ & 102092 & $\sim 7.29$ & $248.40 \pm 4.17(30)$ & $1.46: 1(2500)$ \\
1998 & $\sim 14000$ & $89.57(2723)$ & 77924 & $\sim 5.57$ & $253.00 \pm 3.33(30)$ & $2.24: 1(1000)$ \\
1999 & $\sim 14000$ & $92.34(3245)$ & 84886 & $\sim 6.06$ & $250.40 \pm 5.52(30)$ & $1.72: 1(500)$ \\
\hline Osmia rufa & & & & & $53.40 \pm 1.08(10)$ & $2.68: 1(200)$ \\
\hline 1996 & $\sim 1000$ & $94.32(856)$ & 1832 & $\sim 1.83$ & & $1.35: 1(1200)$ \\
1997 & $\sim 1000$ & $92.51(928)$ & 2237 & $\sim 2.24$ & $52.30 \pm 1.37(10)$ & $2.03: 1(500)$ \\
1998 & $\sim 1000$ & $85.32(1000)$ & 2008 & $\sim 2.01$ & $51.00 \pm 1.24(10)$ & $1.64: 1(300)$ \\
1999 & $\sim 1000$ & $83.15(1000)$ & 2143 & $\sim 2.14$ & $52.80 \pm 1.07(10)$ &
\end{tabular}


be seen from Table 1 that the ratio of sexes varied significantly from year to year.

\section{DISCUSSION}

Both bee species utilize similar nesting niches. In the wider area of Belgrade, O. rufa appears in nature about 2 weeks later than $O$. cornuta, so that about $2 / 3$ of the periods of their activities overlap. We still have no way of explaining why $O$. rufa in OASs did not increase significantly. It would seem that the available floral resources during our investigations were insufficient for significant augmentation of managed $O$. rufa populations. In Italy a managed population of $O$. rufa underwent multifold increase on rape plants, which was not the case with O. cornuta (M. Pinzauti, pers. commun.). We did observe that the more robust female of $O$. cornuta, when appropriating tunnels for nest establishment, sometimes takes over a nest already occupied by an $O$. rufa female. In this way, it probably forces the $O$. rufa female to establish its nest in a new empty reed or else leave the site. But that could not have been the main factor hindering augmentation of $O$. rufa, which was low even when the shelters contained enough narrow tubes suitable for its smaller females.

More than 10,000 cocoons should not be transferred to a single OAS because of the possibility of inadequate pollen levels from surrounding fruit trees at a particular site. Rather, it is more expedient to have several OASs at a distance of at least $500 \mathrm{~m}$ apart from each other, rather than one shelter with an excess of cocoons.

Depending on weather and availability of suitable floral resources in different orchards, two- to three-fold increases have been reported for O. cornifrons in apple orchards (Maeta, 1990), two-fold increases for O. cornuta in almond trees (Bosch, 1994), and five-fold increases for O. lignaria in cherry orchards (Bosch \& Kemp, 1999).

The ratio of sexes in populations of $O$. cornuta and $O$. rufa is favourable if the number of males is between $3: 1$ and $1: 1$. Table 1 indicates that the sex ratio was unfavourable in both species in 1996 and 1998, since the number of males was more than twice as great as the number of females. In $O$. cornuta at the Grocka locality, the ratio in 1996 even achieved a value of $3.22: 1$. This result means that the season during which cocoon formation occurred was very unfavourable.

In conclusion, populations of $O$. cornuta can be reproduced and used as pollinators in the desired numbers in the vicinity of Belgrade only if suitable soil next to the OASs is constantly watered throughout the period of their activity. This presumes that sufficient pasture is available during that period, which lasts about 3 to 4 weeks. For reasons unknown to us, even with this approach, we did not achieve equally successful augmentation of O. rufa numbers. Sex ratios should also be considered, if possible, in establishing augmentation protocol for these species.
ACKNOWLEDGEMENTS. The research was partly supported by the Ministry of Science and Environmental Protection of the Republic of Serbia.

\section{REFERENCES}

BATRA S.W.T. 1998: Management of Hornfaced Bees for Orchard Pollination. University of Idaho, pp. 1-8.

Bosch J. 1994: Improvement of field management of Osmia cornuta (Latreille) (Hymenoptera, Megachilidae) to pollinate almond. Apidologie 25: 71-83.

Bosch J. \& Blas M. 1994: Effect of over-wintering and incubation temperatures on adult emergence in Osmia cornuta Latr. (Hymenoptera, Megachilidae). Apidologie 25: 265-277.

Bosch J. \& KemP W.P. 1999: Exceptional cherry production in an orchard pollinated with blue orchard bees. Bee World 80: 163-173.

Bosch J. \& Kemp W.P. 2000: Development and emergence of the orchard pollinator Osmia lignaria (Hymenoptera: Megachilidae). Envir. Entomol. 29: 8-13.

Bosch J. \& KeMP W.P. 2002: Developing and establishing bee species as crop pollinators: the example of Osmia spp. (Hymenoptera: Megachilidae) and fruit trees. Bull. Entomol. Res. 92: 3-16.

KeMP W.P. \& Bosch J. 2000: Development and emergence of the alfalfa pollinator Megachile rotundata (Hymenoptera: Megachilidae). Ann. Entomol. Soc. Am. 93: 904-911.

Krunić M., Mihajlović L. \& Kulincević J. 1987: Apis mellifera L. and Osmia cornuta Latr. Most significant orchard pollinators in Yugoslavia. Proceedings of Apimondia Congress. Warszawa, $344 \mathrm{pp}$.

Krunić M., Pinzauti A., Felicioli A. \& Stanisavljević L. 1995: Further observations on Osmia cornuta Latr. and O. rufa L. as alternative fruit pollinators, domestication and utilization. Arch. Biol. Sci. (Belgrade) 47: 59-66.

Krunić M.D., Stanisavljević L.Ž., Brajković M.M., Tomanović Ž. \& RAdović I. 2001: Ecological studies of Osmia cornuta (Latr.) (Hymenoptera, Megachilidae) populations in Yugoslavia with special attention to their diapause. Acta Hortic. (ISHS) 561: 297-301.

MaEtA Y. 1990: Utilization of wild bees. Farming Japan 24: 13-19.

Maeta Y. \& Kitamura T. 1974: How to Manage the MameKobachi, Osmia cornifrons (Rad.) for Pollination of the Fruit Crops. Ask Co. Ltd., 16 pp.

SeKITA N. 2001: Managing Osmia cornifrons to pollinate apples in Aomori Prefecture, Japan. Acta Hortic. (ISHS) 561: 303-307.

Torchio P.H. 1976: Use of Osmia lignaria Say (Hymenoptera: Apoidea, Megachilidae) as a pollinator in an apple and prune orchard. J. Kansas Entomol. Soc. 49: 475-482.

Received October 11, 2005; revised and accepted January 19, 2006 